\title{
Efficient induction of specific cytotoxic T lymphocytes to tumor rejection peptide using functional matured 2 day-cultured dendritic cells derived from human monocytes
}

\author{
FUMIAKI TANAKA $^{1,2^{*}}$, HIROSHI YAMAGUCHI ${ }^{1 *}$, NAOTSUGU HARAGUCHI ${ }^{1,2}$, KOHJIRO MASHINO $^{1}$, \\ MITSUHIKO OHTA ${ }^{1}$, HIROSHI INOUE ${ }^{1,2}$ and MASAKI MORI ${ }^{1,2}$
}

\begin{abstract}
${ }^{1}$ Division of Molecular and Surgical Oncology, Department of Molecular and Cellular Biology, Medical Institute of Bioregulation, Kyushu University, 4546 Tsurumihara, Beppu 874-0838; ${ }^{2}$ Core Research for Evolutional Science and Technology (CREST), Japan Science and Technology Agency (JST), 4-1-8 Honcho, Kawaguchi, Saitama 332-0012, Japan
\end{abstract}

Received April 26, 2006; Accepted July 3, 2006

\begin{abstract}
Dendritic cells (DCs) are powerful antigenpresenting cells (APCs), that have so far been applied for cancer specific immunotherapy. Recent results suggest that matured DCs derived from human monocytes have a significant impact on the outcome of vaccination. The conventional generation of mature DCs from human monocytes in vitro has been reported to require 5 days for differentiation with granulocyte macrophage colony-stimulating factor (GM-CSF), interleukin (IL)-4 and 2 days for stimulation. We herein report a new strategy for the functional maturation of monocyte-derived DCs within only 2 days of in vitro culture and the induction of specific cytotoxic T lymphocytes (CTLs) to tumor rejection peptide. The monocytes were incubated for 1 day with GM-CSF and IL-4, followed by activation with a bacterial product, $\mathrm{OK}-432$ and prostaglandin $\mathrm{E}_{2}\left(\mathrm{PGE}_{2}\right)$ for another 1 day (rapid DC). Rapid DC expressed mature DC surface markers as well as chemokine receptor 7 and secreted Th1-type cytokines. The DCs genereated in this study mobilized $\mathrm{Ca}^{2+}$ in response to CCL21/6Ckine and SDF-1, but only marginally did so to Mip-1 $\alpha$. Moreover, when rapid $D C$
\end{abstract}

Correspondence to: Dr Masaki Mori, Division of Molecular and Surgical Oncology, Department of Molecular and Cellular Biology, Medical Institute of Bioregulation, Kyushu University, 4546 Tsurumihara, 874-0838 Beppu, Japan

E-mail: mmori@beppu.kyushu-u.ac.jp

${ }^{*}$ Contributed equally

Abbreviations: PBMC, peripheral blood mononuclear cell; CTL, cytotoxic T lymphocyte; HLA, human leukocytes antigen; CT, cancer-testis; mAb, monoclonal antibody; APC, antigen-presenting cell

Key words: 2-day cultured DC, tumor rejection peptide, cytotoxic T lymphocyte, cancer-specific immunotherapy were compared with mature conventional 7-day DCs, they were equally potent in inducing specific CTLs in vitro. These results indicate that the rapid $D C$ is as effective as the monocyte-derived conventional DCs. The rapid DC would be a potentially useful new cancer-specific immunotherapy.

\section{Introduction}

Dendritic cells (DCs) are considered to be the most powerful antigen-presenting cells (APCs) establishing and controling the primary immune responses. Furthermore, DCs regulate the T-cell response to microbial pathogens, virus-infected cells, dead cells, and tumor cells (1-3). Chemokine receptors, such as CCR7, play an important role for changing the character and function of DCs from immature form to mature form. Mature DCs acquire a capacity to migrate to the $\mathrm{T}$ cell areas of draining secondary lymphoid organs, where they then encounter naïve $\mathrm{T}$ cells and initiate an adaptive immune response (4). Recent developments in the field of in vitro manipulation of DCs now enable us to perform clinical studies of DC-based cancer vaccines for patients with various types of carcinomas, such as gastrointestinal cancer (5), lymphoma (6), and breast cancer (7). When synthetic peptides are used as antigens presented on class I complex on DCs, the administration of peptide-pulsed immature DCs (iDCs) cannot induce full stimulation but it conversely induces antigen-specific T-cell inhibition. As a result, mature DCs should be used for the treatment of cancer (8).

Most experimental and clinical studies currently rely on the in vitro development of DC-like cells from either CD34 ${ }^{+}$ progenitor cells or blood monocytes. It is commonly believed that monocytes are cultured for 5-7 days with GM-CSF and IL-4 to generate immature DCs that have to be activated for another 2-3 days with microbial, proinflammatory, or T cellderived stimuli to obtain mature DCs with a full T stimulatory capacity. However, some reports indicated that there is some dissociation of the period required for generation of DCs between experimental in vitro and in vivo model. Functional DCs have been reported to mature from monocytes after $48 \mathrm{~h}$ culture of peripheral blood mononuclear cells (PBMCs) in the presence of GM-CSF and IL-4 
plus proinflammatory mediators $(9,10)$. However, whether or not these short-term cultured DCs have an ability to encounter naïve $\mathrm{T}$ cells and initiate an adoptive cellular immune response remains to be elucidated.

OK-432, a penicillin-killed and lyophilized preparation of a low-virulence strain ( $\mathrm{Su}$ ) of Streptococcus pynogenes (group A), has been clinically used for the treatment of cancer patients in Japan for more than 20 years. We preveously reported that OK-432 might be useful for inducing an optimal antitumor effect in DC-based immunotherapy in tumorbearing hosts in a mouse model $(11,12)$. In addition, OK-432 have been reported to be useful for stimulating the maturation of monocyte-derived human DCs, and DCs stimulated with OK-432 could efficiently induce CTLs specific to tumor rejection antigen $(11,12)$.

In this study, we show a new strategy for the generation of mature DCs from human monocytes using OK-432 and $\mathrm{PGE}_{2}$ within only 2 days of an in vitro culture. The DCs generated in this study mobilized $\mathrm{Ca}^{2+}$ in response to CCL21/6Ckine and SDF-1, but only marginally did so to Mip-1 $\alpha$. Moreover, when rapid DCs were compared with mature conventional 7-day DCs, they were equally potent in inducing specific CTLs in vitro. Comparing with the rapid DCs and standard 7-day monocyte-derived DCs, the expression of DC activation surface markers, sensitivity to chemokines, the production of Th1-type cytokines such as IL-12 and IFN- $\gamma$, and their ability to induce proliferation and CTLs specific to tumor rejection antigen in vitro. These results indicate that the rapid $D C$ is as effective as the monocyte-derived conventional DCs.

\section{Materials and methods}

Cytokines. Human recombinant IL-2 was a kind gift from Takeda Pharmaceutical (Osaka, Japan). Human recombinant granulocyte/macrophage-colony stimulating factor, human recombinant GM-CSF, IL-4, $\mathrm{PGE}_{2}$, TNF- $\alpha$ and human recombinant IL-7 were purchased from Genzyme/Techne Corporation (Minneapolis, MN, USA). OK-432 was purchased from the Chugai Company, Tokyo, Japan.

Preparation of APCs and CD8-positive T Cells from PBMCs. PBMCs were isolated from healthy donors (HLA-A2402) by standard density gradient centrifugation on Lymphoprep (Nycomed, Oslo, Norway). PBMCs were incubated in AIM-V medium (Life Technologies, Inc.) supplemeted with 2-mercaptoethanol $(50 \mu \mathrm{M})$ and HEPES $(10 \mathrm{mM})$ for $2 \mathrm{~h}$ at $37^{\circ} \mathrm{C}$ in a culture flask to separate an adherent cells and non-adherent cells. The adherent cells were then cultured in the presence of IL-4 $(500 \mathrm{U} / \mathrm{ml})$ and GM-CSF $(500 \mathrm{U} / \mathrm{ml})$ either with TNF- $\alpha(100 \mathrm{ng} / \mathrm{ml})$, with OK432 $(0.1 \mathrm{KE} / \mathrm{ml})$, or with OK432 $(0.1 \mathrm{KE} / \mathrm{ml})+\mathrm{PGE}_{2}(1 \mu \mathrm{M})$ in AIM-V medium for 2 days to generate monocyte-derived dendritic cells (rapid DCs). In some experiments, a 5-day culture was performed to obtain classical DC following maturation with OK432 and $\mathrm{PGE}_{2}$. CD8-positive $\mathrm{T}$ lymphocytes were isolated from non-adherent cells by the MACS separation system (Miltenyi Biotech, Bergisch Gladbach, Germany) using anti-CD8 $\mathrm{mAb}$ coupled with magnetic microbeads according to the manufacturer's instructions. To obtain phytohemagglutinin
(PHA)-stimulated blasts, CD8-negative non-adherent PBMCs were cultured in AIM-V medium containing $1 \mu \mathrm{g} / \mathrm{ml}$ of PHA (Wako Chemicals, Osaka, Japan) and 100 units/ml of IL-2 for 3 days, followed by washing and cultivation in the presence of IL-2 (100 U/ml) for 4 days.

CTL induction using autologous DCs and PHA-blasts. CTL induction was performed according to a procedure described previously (13) with slight modifications. Briefly, autologous DCs were treated with mytomycin C (Kyowa Hakko Co., Ltd., Osaka, Japan) and washed with AIM-V medium. The DCs were then incubated at room temperature (RT) for $2 \mathrm{~h}$ in AIM-V with 32 -microglobulin $(2.5 \mu \mathrm{g} / \mathrm{ml})$ and peptide $(50 \mu \mathrm{g} / \mathrm{ml})$. On day $1,1 \times 10^{5}$ peptide-pulsed DCs/well were plated on 24-well plates and cultured with $1 \times 10^{6} \mathrm{CD}^{+} \mathrm{T}$ cells in $2 \mathrm{ml}$ of AIM-V supplemented with recombinant IL-7 (10 ng/ml). On day 7, 5x105 PHA-blasts were treated with mytomycin $\mathrm{C}$, washed twice, pulsed with $50 \mu \mathrm{g} / \mathrm{ml}$ of peptides, and then were added to each well. On day 8, IL-2 was added to each well at a concentration of $50 \mathrm{U} / \mathrm{ml}$. The peptide stimulation using PHA-blasts as APCs was repeated every 7 days. During CTL induction, the cells were fed with fresh AIM-V medium supplemented with IL-2 $(50 \mathrm{U} / \mathrm{ml})$ every 34 days. On day 28 , the cytotoxic activity of T cells was assessed by a conventional $4-\mathrm{h}{ }^{51} \mathrm{Cr}$ release assay.

Cytotoxicity assay. The lytic activity of CTLs was tested by a conventional ${ }^{51} \mathrm{Cr}$ release assay (14). Briefly, the target cells (TISI cells pulsed with MAGE-3/HLA-A24 peptide IMPKAGLLI) (14) were labeled with $100 \mu \mathrm{Ci}$ of ${ }^{51} \mathrm{Cr}$ for $1 \mathrm{~h}$ at $37^{\circ} \mathrm{C}$, washed three times, and then were resuspended in AIM-V medium. Next, the ${ }^{51} \mathrm{Cr}$-labeled target cells $(4,000$ cells/well) were incubated with various numbers of effector cells for $4 \mathrm{~h}$ at $37^{\circ} \mathrm{C}$ in 96 -well microtiter plates. The radioactivity of the culture supernatant was measured by a gamma counter. The percentage cytotoxicity was calculated as follows: $\%$ cytotoxicity $=($ experimental release - spontaneous release) / (maximum release - spontaneous release) x 100 .

Cytokine release. The supernatant of the effector cells was collected after a 24-h coculture with various target cells and stocked at $-80^{\circ} \mathrm{C}$ until the IL-12, IFN- $\gamma$, and L-4 release assay. A commercially available immunoenzymetric assay kit was used (Immunotech, Marseille, France).

Endocytosis assay. The temperature-dependent uptake of FITC-labeled dextran was used to measure endocytotic function according to a modification of a procedure described previously (15). Fresh DCs were suspended in 0.5 $\mathrm{ml}$ of medium and cultured with FITC-labeled dextran (Sigma) for $60 \mathrm{~min}$ at either $0^{\circ} \mathrm{C}$ or $37^{\circ} \mathrm{C}$. Cells expressing $\mathrm{CD} 11 \mathrm{c}$ were stained by adding anti-CD11c-PE during the last 5 min of the assay; the reaction was terminated by adding ice-cold PBS containing $0.1 \%$ azide. The stained cells were then washed three times, and the CD11 $\mathrm{c}^{+}$population was analyzed immediately for the intracellular accumulation of the FITC label by a cytometric analysis. The degree of endocytosis was determined by comparing the intracellular uptake at $37^{\circ} \mathrm{C}$ with the non-specific binding that occurred at $0^{\circ} \mathrm{C}$. 

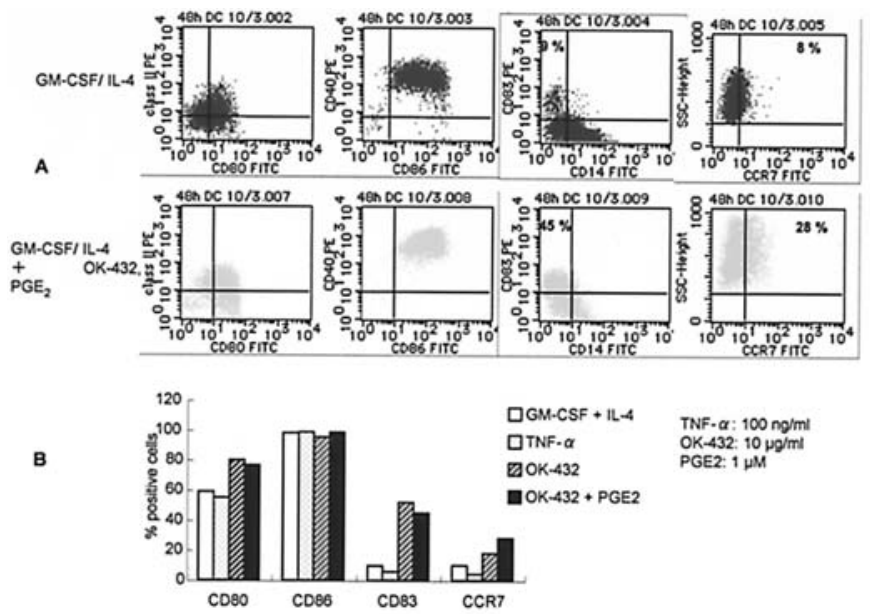

Figure 1. Monocytes incubated with GM-CSF and IL-4 plus OK-432, $\mathrm{PGE}_{2}$ develop into mature DCs within 2 days. Rapid DCs, 2-day culture from peripheral monocytes with GM-CSF, IL-4, OK-432 and $\mathrm{PGE}_{2}$, and classical immature DCs, 7-day culture with GM-CSF and IL-4, were harvested, and then the expression of cell surface antigens was analyzed by flow cytometry. The table depicts the percentage of positively stained cells and MCF intensities. The results are representative of three separate experiments.

$\mathrm{Ca}^{2+}$ mobilization. $\mathrm{Ca}^{2+}$ mobilization in response to CCL21/ 6Ckine was performed as described (16). Briefly, the cells were loaded with Fluo-3AM (Molecular Probes) for $30 \mathrm{~min}$ and warmed to $37^{\circ} \mathrm{C}$ before analysis of flow cytometry. The fluorescence intensity was followed kinetically after addition of 6Ckine, SDF-1, and Mip-1 $\alpha$ on flow cytometer. To induce maximal $\mathrm{Ca}^{2+}$ release, cells were subsequently stimulated with $2.5 \mu \mathrm{g} / \mathrm{ml}$ ionomycin (Sigma).

Statistical evaluation. A statistical analysis was performed using the unpaired two-tailed Student's t-test to compare the cytokine expression. Differences were considered significant when p-value was $<0.05$.

\section{Results}

Phenotype difference between classical DC and 2-day culture $D C$ (rapid $D C$ ). We analyzed the surface phenotype-difference between classical immature DC (7-day culture DCs incubated with GM-CSF and IL-4), and 2-day culture DCs incubated with GM-CSF, IL-4, OK-432 and $\mathrm{PGE}_{2}$. The rapid DCs show a typical surface antigen expression pattern, such as $\mathrm{CD}_{83}{ }^{+}, \mathrm{CD}_{40}{ }^{+}, \mathrm{CCR}^{+}, \mathrm{CD} 14{ }^{-}, \mathrm{CD} 80^{\text {high }}, \mathrm{CD} 86^{\text {high }} \mathrm{MHC}$ $\mathrm{II}^{\text {high }}$ (Fig. 1A). We also compared the maturation status of DCs generated with no maturation stimulation, TNF- $\alpha$ (100 ng/ml), OK432, and OK432 plus $\mathrm{PGE}_{2}$. Fig. 1B shows that incubation with OK-432 or OK432 plus $\mathrm{PGE}_{2}$ generate an increased expression level of CD83 and CCR7 in comparison to that either with TNF- $\alpha$ or without maturation stimulation.

Rapid DC secreted Thl cytokine. To analyze the function of rapid DCs, we measured the level of IL-12, IFN- $\gamma$ and IL-4 in the supernatant of the culture medium. Rapid DCs secreted a high level of IL-12 and IFN- $\gamma$ in comparison to that of TNF- $\alpha$ or without maturation stimulation. On the other hand,

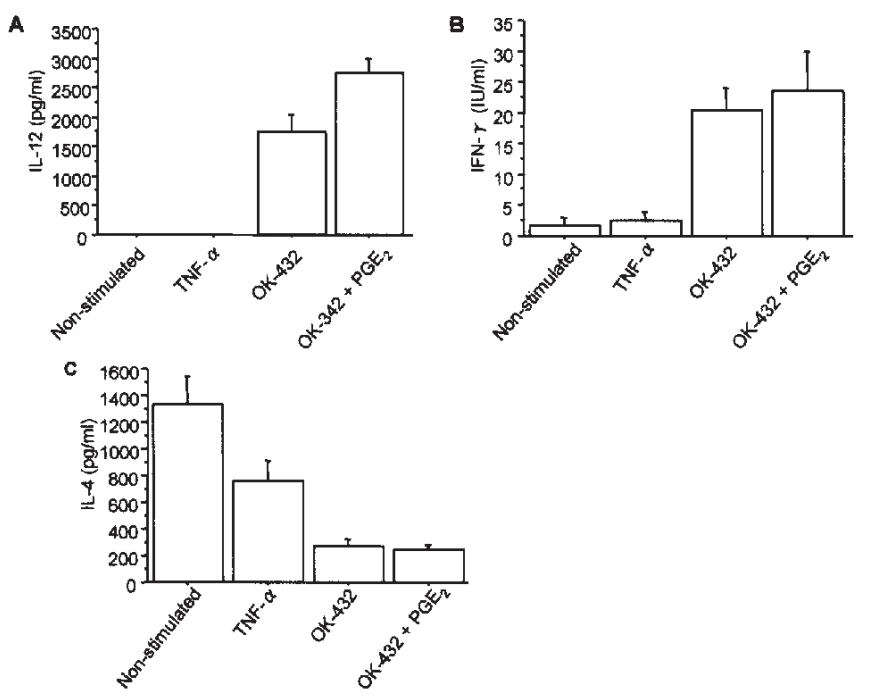

Figure 2. The cytokine expression of 2-day-cultured DCs stimulated with proinflammatory mediators. Each supernatant was collected and the concentrations of IL-12, IL-4, and IFN- $\gamma$ were determined by an immunoenzymetric assay.

the secretion of level of IL-4 was suppressed in rapid DC in comparison to that of TNF- $\alpha$ or without maturation stimulation.

$\mathrm{Ca}^{2+}$ mobilization induced by 6Ckine, and SDF-1, but not Mip-1a in rapid DC. The binding of chemokines to their receptors causes a characteristic increase in the cytosolic calcium. This is one of the earliest biochemical events that occur in response to chemokines $(17,18)$. To examine the intracellular calcium flux, we labeled rapid DCs and classical immature DCs with Fluo-3AM before adding 6Ckine, SDF-1 and Mip-1 $\alpha$. An evaluation of the fluorescence of stimulated cells showed that rapid DCs mobilized $\mathrm{Ca}^{2+}$ in response to CCL21/6Ckine and SDF-1, but only marginally did so to Mip-1 $\alpha$. Immature DC mobilized $\mathrm{Ca}^{2+}$ in response to Mip-1 $\alpha$, but only marginally did so to 6Ckine and SDF-1 (Fig. 3). This result indicated that CCR7 expressed in rapid DC was the functional receptor, which responded to its ligand.

Capture ability of rapid DC. To estimate the ability of the rapid DC and classical immature DC subsets to endocytose, we performed an endocytosis assay using flow cytometry. As shown in Fig. 4, high fluorescence intensities were observed in immature DC in comparison to that of rapid DCs. These results suggest that the rapid DC subsets belong to mature DCs.

Rapid DC generated CTL using MAGE-3/HLA-A24 peptide as well as classical mature DC. To evaluate the ability of rapid DCs to generate CTLs using cancer antigen peptide from naïve $\mathrm{T}$ cells, we performed a cytolytic assay using CTLs cultured with rapid DC. The cytolytic activity was generated against peptide-pulsed target cells when CTLs were co-cultured with mature rapid DC. No cytolysis was generated against the target cells without MAGE-3 restricted with HLA-A24 peptide. The level of cytolytic activity of 
A

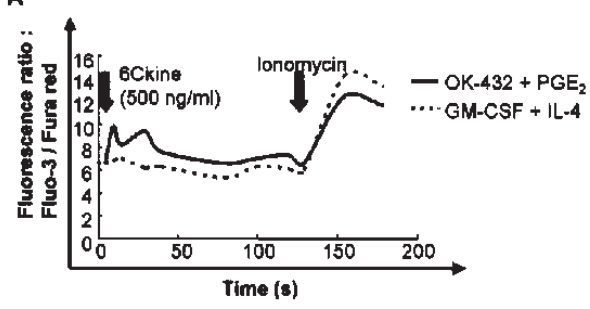

\begin{tabular}{|ll|}
\hline Receptor & Ligand \\
CCR7 & 6Ckine \\
CCR5 & Mip-1 $\alpha$ \\
CXCR4 & SDF-1 \\
\hline
\end{tabular}
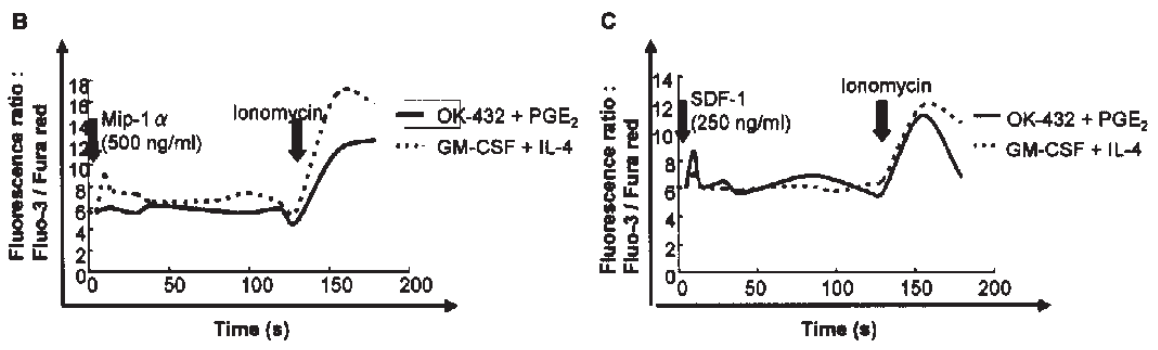

Figure 3. 6Ckine, SDF-1, but not Mip-1 $\alpha$ induced the mobilization of intra-cellular calcium in rapid DC (CCR7, CXCR4-positive, CCR5 negative cells) but did not induce such mobilization in classical immature DC (CCR7, CXCR4-negative, CCR5 positive cells). To examine the intracellular calcium flux, a flow cytometric analysis was performed in rapid DCs and immature DCs preloaded with Fluo-3AM. The fluorescence intensity was followed kinetically. A transient increase in intracellular $\mathrm{Ca}^{2+}$ was recorded in the rapid DC cells after the addition of 6 Ckine, and SDF-1 (200 nM). The data are the percentages of fluorescence intensity relative to the value before the addition of 6 Ckine, and SDF-1. To induce a maximal $\mathrm{Ca}^{2+}$ release, the cells were subsequently stimulated with $2.5 \mu \mathrm{g} / \mathrm{ml}$ ionomycin. The results are representative of three separate experiments.

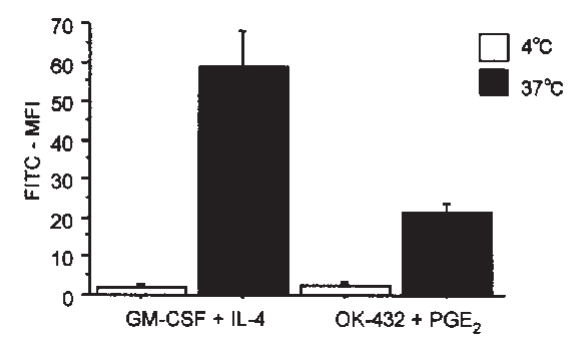

Figure 4. FITC-dextran uptake of rapid DC and classical immature DCs. The DCs subsets were cultured at either $0^{\circ} \mathrm{C}$ or $37^{\circ} \mathrm{C}$ for $90 \mathrm{~min}$ in the presence of FITC-labeled dextran $(1 \mathrm{mg} / \mathrm{ml})$. Cells were counterstained with CD11c-PE, and the intracellular accumulation of FITC-dextran on the CD11c population was determined by cytometric analysis. Numbers indicate relative MCF intensities for the FITC label at $37^{\circ} \mathrm{C}$ minus that at $0^{\circ} \mathrm{C}$. Similar results were obtained for three experiments, and representative results are shown.

CTLs generated with rapid DC was almost the same as that with classical matured DC (Fig. 5). These data indicate that rapid DC showed an adequate maturation-function for the generation of CTLs mediating the Th1 cytokine production.

\section{Discussion}

DC therapy has recently been considered to be one of the strategies for the treatment of patients with advanced cancer, especially for patients who are resistant to conservative therapies, such as surgery, irradiation, and chemotherapy $(5,19)$. Using peptides that were identified to recognize tumor antigen with DC, an effective antitumor effect was observed to mediate the tumor specific immuneresponse (20-22). We reported that an antitumor effect and a tumorspecific immune response were generated in advanced gastrointestinal cancer patients treated with MAGE-3
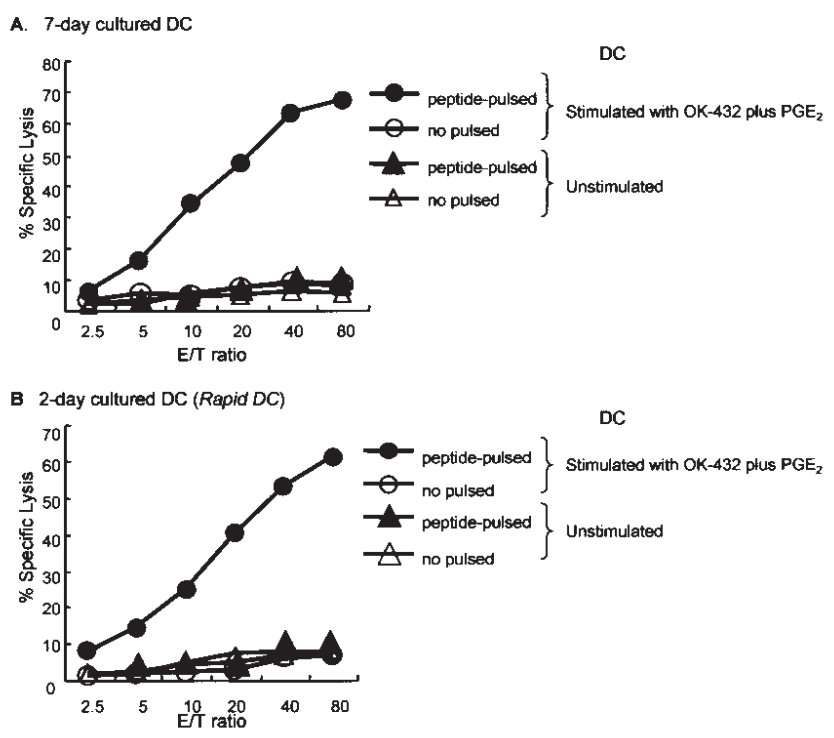

Figure 5. Peptide-pulsed rapid DC induce CTLs specific to the pulsed peptide. The cytotoxic activity of the effector cells induced by stimulation with MAGE-3/HLA-A24 peptide IMPKAGLLI against TISI cells pulsed with the peptide. The effector cells were obtained by stimulating CD8 ${ }^{+} \mathrm{T}$ cells for 28 days with mitomycin C-treated autologous PHA-blasts pulsed with the peptide. TISI cells were pulsed with or without $10 \mu \mathrm{g} / \mathrm{ml}$ of this peptide and then labeled with ${ }^{51} \mathrm{Cr}$. The cytotoxic activity against the TISI cells pulsed either with or without the peptide was assessed at various E:T ratios. (A) 7-day culture DCs, or (B) 2-day culture DC (rapid DCs) were cocultured with effector cells. The cytotoxic activity of the CTLs was determined against peptide-pulsed TISI cells at various E:T ratios by a ${ }^{51} \mathrm{Cr}$ release assay.

peptide and DCs. Furthermore, potent CTL could be induced by the coexistence of DCs and tumor cells that has been destroyed in vitro, and intratumoral DC injection following 
anticancer drug treatment (8). To improve these strategies using DCs, one problem is that we need 7 days to generate DCs from peripheal monocytes.

In this study, we generated 2-day culture DCs, namely rapid DCs, from peripheral monocytes. We then analyzed the surface antigen expression, cytokine production, capture ability of antigen, chemokine/chemokine receptor response, and CTL induction. These data revealed the rapid DCs have an equal function to that of 7-day classical mature DCs.

Dauer et al (9) have reported on functional DCs generated in $48 \mathrm{~h}$ using GM-CSF, IL-4 and proinflammatory mediators. Those DCs were able to induce tetanus toxoid specific $\mathrm{T}$ cells. Alldawi et al (10) reported on DCs generated in $48 \mathrm{~h}$ using GM-CSF, IL-4 and LPS and INF- $\gamma$. Recently, Dauer et al (23) reported that DCs developed in $48 \mathrm{~h}$ primed CTLs using Melan-A/HLA-A0201 peptide. These results were consistent with those from our study. Furthermore, we showed the following novel findings: i) strong CTLs were generated using MAGE-3/HLA-A24 peptide (not tetanus toxin) and rapid DCs from human monocytes, and ii) the cytolytic activity was generated against MAGE-3 positive target cells. These results indicate that this strategy may therefore enhance the effectiveness of the clinical settings for human cancer patients.

We demonstrated rapid DCs to be generated in the conditioned medium of GM-CSF, IL-4, OK-432 and $\mathrm{PGE}_{2}$. Our previous study indicated a significantly high expression of class II, CD80, and CD40 detected in OK-432-treated DCs in comparison with that of control DCs. OK-432 is a penicillin-killed streptococcal preparation, which is reported to be a potent inducer of Th1-type cytokines (24). A lipoteichoic acid-related molecule, designated OK-PSA, isolated from OK-432 has been reported as a potent inducer of Th1-type cytokines (25). Moreover, OK-PSA was reported to be involved in the toll-like receptors, that are expressed in myelomonocytic elements, and it thus play a fundamental role in the pathogen recognition and activation of innate immunity $(26,27)$. It is possible that OK-PSA might have an effect on the progenitor cells of DCs, such as monocytes, in the OK-432-treated cachectic mice, thereby improving their function to elicit antitumor immune responses. The results obtained in this study are consistent with our recent findings of an in vitro study in mice, in which functional mature DCs were generated in a conditioned medium.

Taken together, the rapid DCs generated with a 2-day culture from peripheral monocytes with GM-CSF, IL-4, OK-432 and $\mathrm{PGE}_{2}$ were found to have an equal function to that of 7-day culture mature DCs. The generation of rapid DC not only reduces the labor, costs, and time required for in vitro DC development, but may also be useful as a cancerspecific immunotherapy. This approach might therefore be applicable to patients with cancer.

\section{Acknowledgements}

We thank Ms. T. Shimooka, K. Ogata, M. Oda and H. Yasunami of our laboratory for their excellent technical assistance. This work was supported by Grant sponsors: CREST JST; Uehara Memorial Foundation; Japan Society for the Promotion of Science (JSPS) Grant-in-Aid for Scientific Research; Grant numbers 17015032, 17109013, 17591411, 17591413, 17015032, and 16390381, and Cancer Translational Research Project from Ministry of Education, Culture, Sports, Science and Technology.

\section{References}

1. Steinman RM and Mellman I: Immunotherapy: bewitched, bothered and bewildered no more. Science 305: 197-200, 2004.

2. Inaba K, Turley S, Yamaide F, Iyoda T, Mahnke K, Inaba M, Pack M, Subklewe M, Sauter B, Sheff D, Albert M, Bhardwaj N, Mellman I and Steinman RM: Efficient presentation of phagocytosed cellular fragments on the major histocompatibility complex class II products of dendritic cells. J Exp Med 188: 2163-2173, 1998

3. Mellman I and Steinman RM: Dendritic cells: specialized and regulated antigen processing machines. Cell 106: 255-258, 2001.

4. Hirao M, Onai N, Hiroishi K, Watkins SC, Matsushima K, Robbins PD, Lotze MT and Tahara H: CC chemokine receptor-7 on dendritic cells is induced after interaction with apoptotic tumor cells: critical role in migration from the tumor site to draining lymph nodes. Cancer Res 60: 2209-2217, 2000

5. Sadanaga N, Nagashima H, Mashino K, Tahara K, Yamaguchi H, Ohta M, Fujie T, Tanaka F, Inoue H, Takesako K, Akiyoshi T and Mori M: Dendritic cell vaccination with MAGE peptide is a novel therapeutic approach for gastrointestinal carcinomas. Clin Cancer Res 7: 2277-2284, 2001.

6. Buchler T, Michalek J, Kovarova L, Musilova R and Hajek R: Dendritic cell-based immunotherapy for the treatment of hematological malignancies. Hematology 8: 97-104, 2003.

7. Hernando JJ, Park TW and Kuhn WC: Dendritic cell-based vaccines in breast and gynaecologic cancer. Anticancer Res 23: 4293-4303, 2003

8. Tanaka F, Yamaguchi H, Ohta M, Mashino K, Sonoda H, Sadanaga N, Inoue $\mathrm{H}$ and Mori M: Intratumoral injection of dendritic cells after treatment of anticancer drugs induces tumorspecific antitumor effect in vivo. Int J Cancer 101: 265-269, 2002.

9. Dauer M, Obermaier B, Herten J, Haerle C, Pohl K, Rothenfusser S, Schnurr M, Endres S and Eigler A: Mature dendritic cells derived from human monocytes within 48 hours: a novel strategy for dendritic cell differentiation from blood precursors. J Immunol 170: 4069-4076, 2003.

10. Alldawi L, Takahashi M, Narita M, Ayres F, Tsukada N, Osman Y, Furukawa T and Aizawa Y: Effect of prostaglandin E2, lipopolysaccharide, IFN-gamma and cytokines on the generation and function of rapid-DC. Cytotherapy 7: 195-202, 2005.

11. Mashino K, Sadanaga N, Tanaka F, Ohta M, Yamaguchi H and Mori M: Effective strategy of dendritic cell-based immunotherapy for advanced tumor-bearing hosts: the critical role of Th1dominant immunity. Mol Cancer Ther 1: 785-794, 2002.

12. Nakahara S, Tsunoda T, Baba T, Asabe S and Tahara H: Dendritic cells stimulated with a bacterial product, OK-432, efficiently induce cytotoxic T lymphocytes specific to tumor rejection peptide. Cancer Res 63: 4112-4118, 2003.

13. Yamaguchi $\mathrm{H}$, Tanaka $\mathrm{F}$, Ohta $\mathrm{M}$, Inoue $\mathrm{H}$ and Mori $\mathrm{M}$ : Identification of HLA-A24-restricted CTL epitope from cancertestis antigen, NY-ESO-1 and induction of a specific antitumor immune response. Clin Cancer Res 10: 890-896, 2004

14. Tanaka F, Fujie T, Tahara K, Mori M, Takesako K, Sette A, Celis $\mathrm{E}$ and Akiyoshi T: Induction of antitumor cytotoxic $\mathrm{T}$ lymphocytes with a MAGE-3-encoded synthetic peptide presented by human leukocytes antigen-A24. Cancer Res 57: 4465-4468, 1997.

15. Sallusto F, Cella M, Danieli C and Lanzavecchia A: Dendritic cells use macropinocytosis and the mannose receptor to concentrate macromolecules in the major histocompatibility complex class II compartment: downregulation by cytokines and bacterial products. J Exp Med 182: 389-400, 1995.

16. Yanagihara S, Komura E, Nagafune $J$, Watarai $H$ and Yamaguchi Y: EBI1/CCR7 is a new member of dendritic cell chemokine receptor that is up-regulated upon maturation. J Immunol 161: 3096-3102, 1998. 
17. Muller A, Homey B, Soto H, Ge N, Catron D, Buchanan ME, McClanahan T, Murphy E, Yuan W, Wagner SN, Barrera JL, Mohar A, Verastegui E and Zlotnik A: Involvement of chemokine receptors in breast cancer metastasis. Nature 410: 50-56, 2001.

18. Burger JA, Burger M and Kipps TJ: Chronic lymphocytic leukemia B cells express functional CXCR4 chemokine receptors that mediate spontaneous migration beneath bone marrow stromal cells. Blood 94: 3658-3667, 1999.

19. Banchereau J, Palucka AK, Dhodapkar M, Burkeholder S, Taquet N, Rolland A, Taquet S, Coquery S, Wittkowski KM, Bhardwaj N, Pineiro L, Steinman R and Fay J: Immune and clinical responses in patients with metastatic melanoma to CD34(+) progenitor-derived dendritic cell vaccine. Cancer Res 61: 6451-6458, 2001

20. Brossart P, Wirths S, Brugger W and Kanz L: Dendritic cells in cancer vaccines. Exp Hematol 29: 1247-1255, 2001

21. Dubsky P, Ueno H, Piqueras B, Connolly J, Banchereau J and Palucka AK: Human dendritic cell subsets for vaccination. J Clin Immunol 25: 551-572, 2005.

22. Fay JW, Palucka AK, Paczesny S, Dhodapkar M, Johnston DA, Burkeholder S, Ueno H and Banchereau J: Long-term outcomes in patients with metastatic melanoma vaccinated with melanoma peptide-pulsed CD34(+) progenitor-derived dendritic cells. Cancer Immunol Immunother 6: 1-10, 2005.
23. Dauer M, Schad K, Herten J, Junkmann J, Bauer C, Kiefl R, Endres $\mathrm{S}$ and Eigler A: FastDC derived from human monocytes within $48 \mathrm{~h}$ effectively prome tumor antige-specific cytotoxic $\mathrm{T}$ cells. J Immunol Method 302: 145-155, 2005.

24. Fujimoto T, Duda RB, Szilvasi A, Chen X, Mai M and O'Donnell, MA: Streptococcal preparation OK-432 is a potent inducer of IL-12 and a T helper cell 1 dominant state. J Immunol 158: 5619-5626, 1997.

25. Okamoto M, Oshikawa T, Ohe G, Furuichi S, Nishikawa H, Tano T, Bando T, Yoshida H, Matsubara S, Matsuno T, Saito M and Sato M: Comparison of cytokine-inducing activity in a lipoteichoic acid-related molecule isolated from a penicillinkilled group A Streptococcus and from untreated bacteria. Int Immunopharmacol 1: 1957-1968, 2001.

26. Okamoto M, Oshikawa T, Ohe G, Nishikawa H, Furuichi S, Tano T, Moriya Y, Saito M and Sato M: Severe impairment of anti-cancer effect of lipoteichoic acid-related molecule isolated from a penicillin-killed Streptococcus pyogenes in toll-like receptor 4-deficient mice. Int Immunopharmacol 1: 1789-1795, 2001.

27. Muzio M, Bosisio D, Polentarutti N, D'Amico G, Stoppacciaro A, Mancinelli R, van't Veer C, Penton-Rol G, Ruco LP, Allavena P and Mantovani A: Differential expression and regulation of tolllike receptors (TLR) in human leukocytes: selective expression of TLR3 in dendritic cells. J Immunol 164: 5998-6004, 2000. 